\title{
Las migraciones maritimas irregulares: las islas en la red de rutas
}

Elaborado por Dirk Godenau y Daniel Buraschi

Las Islas Canarias forman parte de una de las rutas marítimas irregulares de la emigración africana hacia el continente europeo. El reducido tamaño de las islas, tanto en términos geográficos como demográficos y económicos, conlleva un reto específico en la gestión de la acogida, en particular si consideramos la relativa imprevisibilidad del fenómeno. Por esta razón es importante abordar algunas claves para comprender la evolución de las migraciones marítimas irregulares hacia las islas Canarias en la última década.

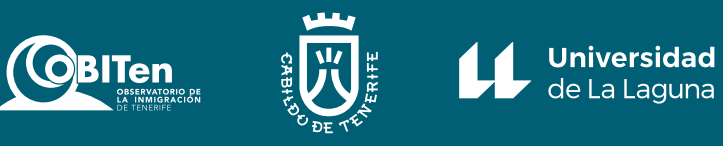




\section{Intro: Islas en la red de rutas}

Si el mar cubre cuatro quintas partes de la superficie del globo terráqueo, no es de extrañar que, antes del desarrollo de la aeronáutica, la movilidad de las personas entre continentes estuviera estrechamente vinculada al transporte marítimo y pasara por un mar de islas; islas que generaban puntos de apoyo logístico para estas rutas y que canalizaban las migraciones internacionales. $Y$ aunque hoy en día la movilidad intercontinental de las personas se realiza en gran medida por vía aérea, las islas siguen ocupando un lugar especial en la bibliografía sobre las migraciones internacionales, particularmente en su vertiente de migraciones marítimas irregulares.

¿Por qué optan las personas que carecen de permiso para la inmigración regular por la travesía marítima irregular? Se debe a una combinación de varias razones. Abordar un medio de transporte aéreo regular conlleva el control de la identidad del pasajero; el espacio aéreo está bajo la supervisión de una tupida red tecnológica y, por ende, el coste del traslado aéreo irregular es elevado. A su vez, en la relación coste-beneficio de la opción marítima irregular intervienen otros factores como la valoración de posibles rutas terrestres alternativas, la distancia y los riesgos propios del medio marítimo, las posibilidades de embarcarse en la costa de salida sin ser interceptado y la probabilidad de detección y posterior derivación hacia la costa de destino.

Es en este contexto donde las islas adquieren una posición intersticial destacada, porque su localización interpuesta entre continentes reduce las distancias y, si pertenecen al país de destino de referencia (islas de la Unión Europea, por ejemplo), arribar en una de ellas puede significar para el migrante el haber cruzado finalmente la frontera, y que, posiblemente, sea trasladado posteriormente al espacio continental. La política australiana de inmigración es ilustrativa de las excepciones a esta regla, al excluir algunas de sus islas del territorio nacional en términos de inmigración. En el caso de las islas pertenecientes a la Unión Europea, no se ha establecido tal excepcionalidad.

Las islas europeas se cuentan por centenares, pero son solo algunas las que han adquirido notoriedad en las rutas migratorias y en la atención de los medios de comunicación. Lampedusa, Lesbos, Malta y Canarias son ejemplos destacados de espacios insulares fronterizos que pertenecen, a su vez, a diferentes rutas migratorias. Su protagonismo varía a lo largo del tiempo según evolucionan las rutas migratorias y el peso que tienen éstas en el conjunto de las migraciones irregulares.

Los análisis que se han hecho de las migraciones irregulares arribadas a estas islas resaltan que el reducido tamaño de estos espacios, tanto en términos geográficos como demográficos y económicos, conlleva un reto en la gestión de la acogida, particularmente si las llegadas tienen una evolución volátil en el tiempo y no se cuenta con infraestructuras fijas para tales tareas. Además, la discontinuidad terrestre que caracteriza el hecho insular implica para las personas migrantes que su salida de la isla, a diferencia del contexto continental, cuenta con menores posibilidades de un traslado inadvertido, al existir mayores controles en las vías aéreas y marítimas. Finalmente, las islas suponen para la vigilancia de las fronteras exteriores una considerable ampliación del área bajo supervisión, en comparación con una frontera continental continua. 


\section{Las rutas migratorias mediterráneas y atlántica}

Las estadísticas que publican los informes anuales y trimestrales de FRONTEX sobre las detecciones de cruces irregulares de las fronteras exteriores de la Unión Europea distinguen entre ocho rutas (ver mapa 1), cuya tipología es resultante de una combinación de su naturaleza terrestre o marítima con su ubicación geográfica (oriental, central, occidental). Las dos rutas implicadas en las llegadas de las migraciones irregulares marítimas a España son la ruta mediterránea occidental y la atlántica (África occidental).

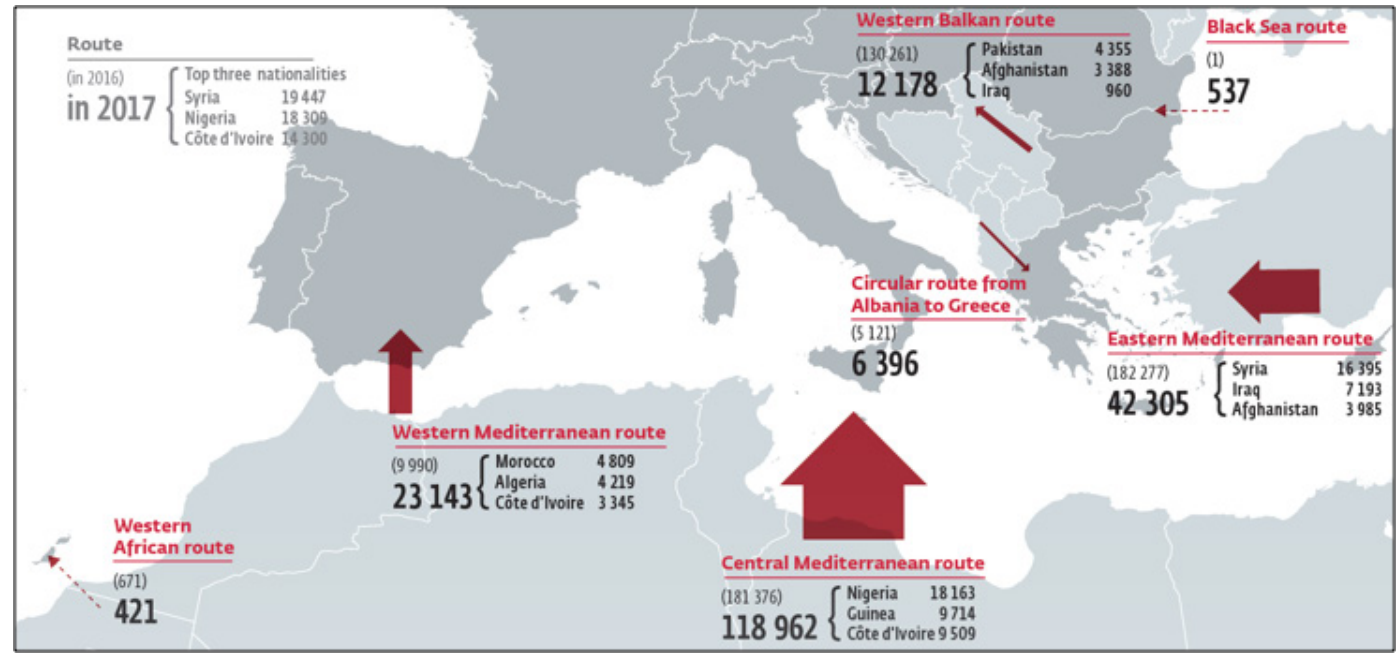

La evolución reciente del uso de estas rutas se resumen en el siguiente patrón general (ver Tabla 1):

- Los años 2015 y 2016 arrojan cifras excepcionalmente elevadas, debido a la repentina intensificación de las llegadas por las rutas del Mediterráneo oriental y la ruta terrestre de los Balcanes occidentales. El año 2017 refleja una vuelta rápida a los niveles previos a esta "crisis de los refugiados".

- Relacionado con lo anterior, el peso de las rutas occidentales del Mediterráneo y Atlántico muestran una evolución temporalmente a la baja (un 0,4\% del total de detecciones en 2015) y posteriormente experimentan un alza repentino que las ubica en el año 2017 en una cuota del 11,3\% (23.143 detecciones) del Mediterráneo occidental y el $0,2 \%$ de la ruta atlántica (421 personas). A pesar de este cambio reciente, las rutas restantes del Mediterráneo siguen canalizando volúmenes muy superiores y su peso se aproxima al $80 \%$ del total.

- Dentro de las migraciones marítimas irregulares que llegan a España, la ruta atlántica vía Canarias ocupa en 2017 un lugar residual del 1,8\%. Esta situación dista de la vivida en los años 2005 a 2007 (gráfico 1), cuando la ruta atlántica se había convertido temporalmente en el principal canal de las llegadas. Además, las 874 detecciones en esta ruta en el año 2015 son más del doble de las registradas en 2017 (421). Es a lo largo de 2018 cuando se empieza a registrar un crecimiento notable; hasta finales de octubre las detecciones en Canarias se cifran en 1.215 y, por ende, a finalizar el año 2018 estas llegadas habrán superado las cifras registradas en 2015.
Mapa 1

Detecciones de cruces irregulares de las fronteras exteriores de la UE (2017)

Fuente

Frontex Risk Analysis for 2018, p. 8. 
Tabla 1

Detecciones de cruce irregular de fronteras exteriores de la Unión Europea.

Fuente

Frontex Risk Analysis for 2018, p. 43.

\begin{tabular}{l|c|c|c|c|c|c}
\hline \multicolumn{1}{c|}{ Rutas } & $\mathbf{2 0 1 4}$ & $\mathbf{2 0 1 5}$ & $\mathbf{2 0 1 6}$ & $\mathbf{2 0 1 7}$ & $\begin{array}{c}\text { \% del } \\
\text { total } \\
\mathbf{2 0 1 7}\end{array}$ & $\begin{array}{c}\text { \% crec. } \\
\text { sobre } \\
\text { año pre- } \\
\text { vio }\end{array}$ \\
\hline Mediterráneo Central & 170.664 & 153.946 & 181.376 & 118.962 & 58,0 & -34 \\
\hline Mediterráneo Oriental & 50.834 & 885.386 & 182.277 & 42.305 & 21,0 & -77 \\
\hline Marítimo & 44.057 & 873.179 & 174.605 & 34.732 & 82,0 & -80 \\
\hline Terrestre & 6.777 & 12.207 & 7.672 & 7.573 & 18,0 & $-1,3$ \\
\hline $\begin{array}{l}\text { Mediterráneo } \\
\text { Occidental }\end{array}$ & 7.243 & 7.004 & 9.990 & 23.143 & 11,0 & 132 \\
\hline Marítimo & 4.749 & 5.740 & 8.641 & 21.632 & 93,0 & 150 \\
\hline Terrestre & 2.494 & 1.264 & 1.349 & 1.511 & 6,5 & 12 \\
\hline Balcanes Occidentales & 43.357 & 764.038 & 130.261 & 12.178 & 5,9 & -91 \\
\hline Ruta circular Albania a & 8.841 & 8.932 & 5.121 & 6.396 & 3,1 & 25 \\
Grecia & 1.275 & 1.927 & 1.349 & 776 & 0,4 & -42 \\
\hline Fronteras del Este & 433 & 68 & 1 & 537 & 0,3 & 53600 \\
\hline Mar Negro & 276 & 874 & 671 & 421 & 0,2 & -37 \\
\hline África Occidental & 10 & 2 & 1 & 1 & 0,0 & 0 \\
\hline Otros & $\mathbf{2 8 2 . 9 3 3}$ & & $\mathbf{5 1 1 . 0 4 7}$ & $\mathbf{2 0 4 . 7 1 9}$ & $\mathbf{1 0 0}$ & $\mathbf{1 0 0}$ \\
\hline Total & & & &
\end{tabular}

- Las rutas marítimas superan en la actualidad con creces los traslados por rutas terrestres en lo que se refiere a las detecciones en las fronteras exteriores de la Unión Europea. Una vez "cerrada" la vía terrestre de los Balcanes, en el año 2017 el 86,1\% de las detecciones corresponde a las rutas marítimas. Como indica Frontex $(2018$, p. 8), "de cara al futuro, la migración marítima irregular, particularmente la asociada a las rutas mediterráneas, permanecerá como modus operandi principal para el cruce ilegal de las fronteras exteriores de la Unión Europea".

Los cambios que se observan en las rutas son el resultado de un complejo entresijo de factores. Inciden, entre otros, las presiones emigratorias generadas por hechos estructurales y coyunturales en los países de origen; las transitabilidad y riesgo de las rutas utilizadas antes de llegar a las costas de las que parten las embarcaciones; y la impermeabilidad relativa de las rutas marítimas (probabilidad de interceptación antes de salir, riesgos y precios del trayecto marítimo, condiciones de llegada y acogida, probabilidad de un posterior traslado al destino final deseado). En este conjunto de probabilidades de tránsito no solo juegan un papel importante las acciones restrictivas a lo largo de cada una de las rutas (control migratorio), también se deben contemplar las acciones de (re)permeabilización por parte de los intermediarios. La apertura de rutas alternativas, la introducción de cambios tecnológicos (medios de transporte, comunicaciones, contra-vigilancia) y la construcción de opacidades selectivas y temporales en las fronteras, figuran entre las funciones desempeñadas por estos intermediarios.

En este sentido, y a pesar de su frecuente uso en los discursos mediáticos y hasta académicos, la explicación de la evolución de las rutas no debería descansar sobre metáforas físicas como "el agua se busca camino" o "si presionas sobre un lado de un globo, se expande hacia el otro lado". Estas metáforas no son capaces de dimensionar el proceso 
social que constituye las fronteras: las rutas se construyen y se gestionan a través de la interacción entre las fuerzas facilitadoras y restrictivas. Por parte del control migratorio, se construye una disuasión migratoria multicapa, desde la intervención en lugares previos a la frontera europea (acuerdos de colaboración), pasando por la vigilancia de la propia frontera, y hasta después de haberla superado (control interior). En este sentido, la impermeabilización de las fronteras es mucho más que vallas y muros. Estos obstáculos físicos no suelen ser los más efectivos ni eficientes en la disuasión, pero sí lo son a la hora de visibilizar ante la opinión pública una supuestamente férrea voluntad política.

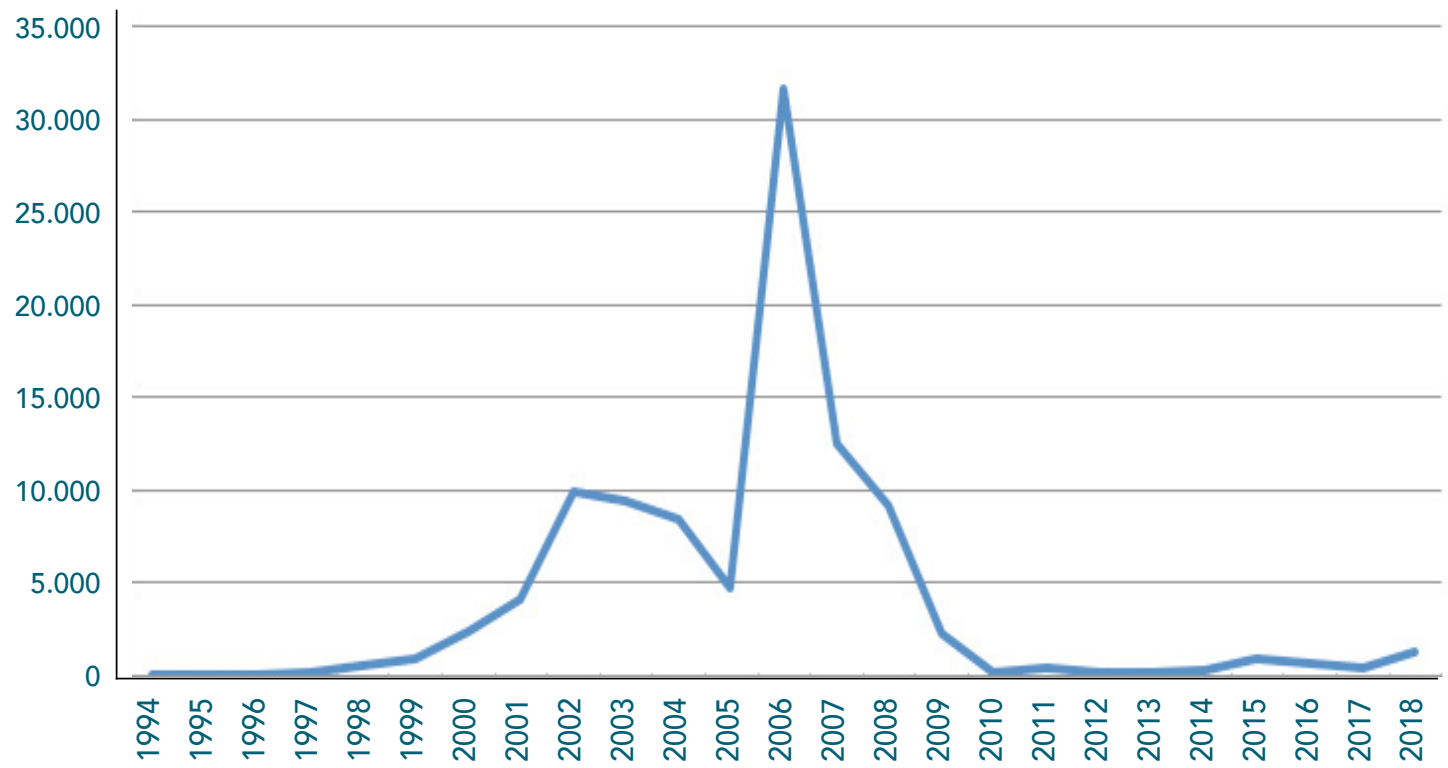

Fronteras, medios de comunicación y opinion pública

Las fronteras no se pueden concebir como límites fijos, sino como instituciones socialmente construidas que reflejan relaciones de poder y que están sujetas a un proceso de creación continua. Las fronteras, su significado y su eficacia social, se construyen y reconstruyen a través de los discursos de las instituciones políticas, de los medios de comunicación y de la sociedad civil. Para comprender las dinámicas de las fronteras es importante reconocer su función simbólica, y además, cómo los medios de comunicación y la opinión publica contribuyen al fortalecimiento de las mismas, a su resignificación o a su contestación.

La sociedad civil, generalmente, vive las fronteras como una experiencia principalmente mediática, en el sentido en que la mayoría de las personas tienen una visión de las fronteras condicionada por los medios de comunicación. Si parte de nuestro conocimiento depende de los medios, la agenda social estará fuertemente influida por la mediática: los elementos sobresalientes en la agenda de los medios se transforman en sobresalientes en la opinión pública. Los medios de comunicación tienen la capacidad de enfocar el interés del público sobre determinadas cuestiones y, del mismo modo, son capaces de excluir determinados eventos. Las migraciones irregulares por vía marítima, por ejemplo, a pesar de no ser la principal vía de entrada de la inmigración irregular, representan uno de los temas más recurrentes en los medios de comunicación cuando se habla de los fenómenos migratorios. Está práctica sobredimensiona en la opinión pública la intensidad, el volumen y el impacto de las migraciones marítimas irregulares y, además, invisibiliza

\section{Gráfico 1}

Personas detenidas que han llegado a Canarias a bordo de embarcaciones por lugares no habilitados entre $1994 \mathrm{y}$ 2018.

Nota: datos provisionales de 2018 hasta finales del mes de octubre.

Fuente

Ministerio del Interior y prensa especializada. 
otros temas relacionados con las migraciones, como las experiencias de vida de las personas migrantes, sus aportaciones a la sociedad y las acciones de la sociedad civil.

\section{Recuadro 1. La representación de las migraciones marítimas irregulares en los periódicos locales de Tenerife}

El análisis de los titulares de las noticias publicadas en algunos de los principales periódicos de Canarias (El Día, Diario de Avisos, La Opinión y Canarias 7) muestra el claro predominio, cuando se habla de migraciones, de los temas vinculados a las fronteras marítimas y la entrada irregular de personas inmigrantes. Hay que destacar que, en general, la inmigración no ha sido un tema particularmente relevante en la agenda mediática canaria. A lo largo de 24 meses, en los cuatros periódicos objeto de estudio, se han publicado 368 noticias relacionadas con el fenómeno migratorio, de las cuales 192 están directamente relacionadas con las migraciones que afectaban a las Islas Canarias.

Tabla 2

Distribución de los encuadres noticiosos de las noticias publicadas en 2016 y 2017 relacionadas con el fenómeno migratorio en Canarias (EI Día, Diario de Avisos, La Opinión y Canarias 7).

\begin{tabular}{l|c}
\hline Encuadres & $\%$ \\
\hline Acceso a servicios (sanitario, educación, ayudas sociales, etc.) & 3,6 \\
\hline Acciones solidarias a favor de inmigrantes y refugiados & 1,0 \\
\hline Acogida de refugiados y de menores & 4,7 \\
\hline Afiliación de extranjeros a la seguridad social & 11,5 \\
\hline Análisis del fenómeno migratorio & 4,2 \\
\hline Centro de Internamiento de Extranjeros & 5,2 \\
\hline Denuncia de violación de los derechos de los inmigrantes & 5,2 \\
\hline Emigración de canarios & 3,6 \\
\hline Experiencia vital de las personas migrantes & 0,5 \\
\hline Fronteras marítimas y entrada irregular & 48,0 \\
\hline Política migratoria & 5,2 \\
\hline Procesos de nacionalización & 2,6 \\
\hline Proyectos sociales vinculados a la acogida e integración de inmigrantes & 3,1 \\
\hline Víctimas de explotación sexual & 1,6 \\
\hline
\end{tabular}

Entre 2016 y 2017, el 48\% de las noticias estaban vinculadas a la frontera marítima y a la entrada irregular de inmigrantes. Este encuadre temático incluye noticias sobre la llegada de pateras, la detención de patrones de pateras, el rescate de inmigrantes por parte de salvamento marítimo y la muerte de inmigrantes en su intento de llegar a las islas por vía marítima. Un aspecto particularmente importante para comprender la imagen prototípica que la sociedad canaria puede tener de las personas inmigrantes es que, si nos centramos en los colectivos de inmigrantes que protagonizan las noticias, los inmigrantes en situación administrativa irregular son citados en dos tercios de las mismas. Estos datos muestran como las migraciones marítimas irregulares en los años 2016 y 2017, a pesar de estar lejos de representar un fenómeno numéricamente significativo, se encuentran en el centro de la agenda mediática cuando se habla de migraciones en Canarias. 


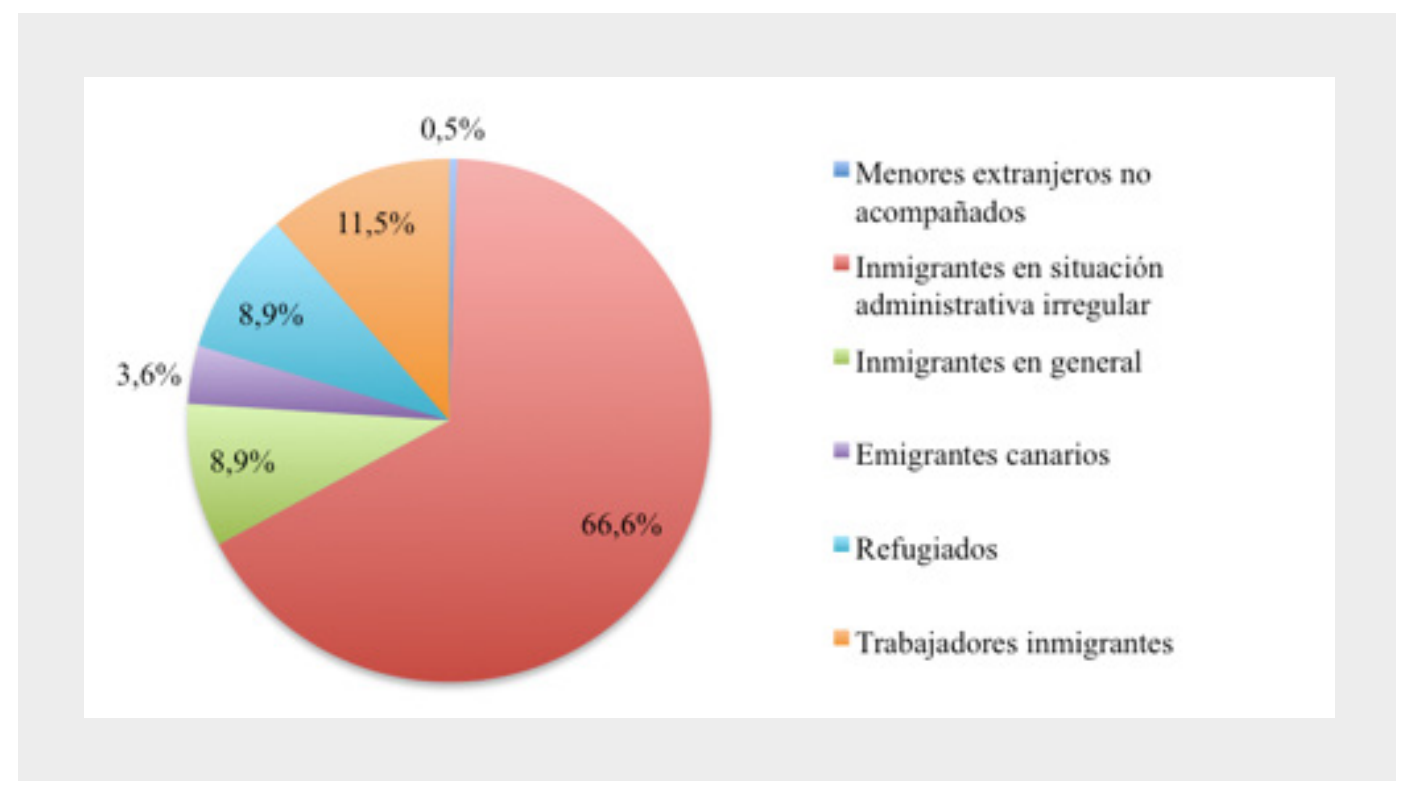

Gráfico 2

Distribución de los colectivos que protagonizan las noticias publicadas sobre migraciones en Canarias

Además de definir los temas relevantes, los medios de comunicación ofrecen siempre, explícita o implícitamente, un determinado encuadre de la noticia, esto significa que en la noticia vehicula determinados valores, creencias, expectativas y que influyen en los destinatarios. Encuadrar una noticia significa enfocar un tema de una forma determinada; fijar una agenda de atributos; seleccionar las expresiones clave que definen el discurso; dotar de énfasis a algunas de estas expresiones; y definir una "idea organizadora central" para construir la historia informativa.

Simplificando podríamos decir que en España, como en el resto de los países europeos, existen dos encuadres dominantes a la hora de informar sobre las fronteras y las migraciones irregulares marítimas: un "enfoque securitario" y un "enfoque humanitario". El enfoque securitario hace hincapié en el peligro que representan las migraciones irregulares, las personas migrantes son presentadas como una amenaza y se hace hincapié en la necesidad de protegerse frente a la llegada de inmigrantes. El enfoque humanitario presenta a las personas migrantes como víctimas que hay que socorrer 0 , al menos, hacia las cuales hay que sentir compasión. Estos encuadres pueden tener un importante impacto en la opinión pública: en el primer caso, puede generarse alarma social y la ciudadanía podría presionar para que se refuercen las fronteras y se endurezcan los controles. En el segundo caso, la opinión pública podría exigir un cambio en la política migratoria, la intervención de la administración en acciones de salvamiento y su implicación en acciones solidarias.

Entre medios de comunicación, discurso político y opinión pública existe una relación circular. Por una parte, el discurso político y los medios pueden influir en la opinión pública; por el otro, la opinión pública, sobre todo en un contexto en el cual las redes sociales y el discurso on-line en general están teniendo un peso importante en nuestra comunicación diaria, puede tener un importante impacto en los medios de comunicación, en el discurso y en la acción política. En los últimos años, por ejemplo, diferentes trágicos eventos relacionados con las migraciones marítimas irregulares han tenido una enorme trascendencia social, que a su vez ha producido un importante, aunque efímero, impacto político en la gestión de las fronteras. El 3 de octubre de 2013, por ejemplo, el naufragio y muerte de 360 personas frente a la isla de Lampedusa generó una presión social que llevó al gobierno italiano a activar una importante y amplia operación de control y rescate denominada "Mare Nostrum", que funcionó durante un año y transformó la frontera 
marítima cercana a Lampedusa de un espacio "estrictamente securitario", en el cuál se priorizaban las acciones de control, en un "espacio humanitario", en el cual se hacía más hincapié en el rescate de personas migrantes.

Sin embargo, el caso más paradigmático de la influencia de la opinión pública en el proceso de construcción y deconstrucción de la frontera ha sido la fotografía de Aylan Kurdi, un niño sirio que apareció ahogado en una playa de Turquía el 2 de septiembre de de 2015. Al día siguiente, la imagen se transformaba en un fenómeno viral capaz de definir y resumir la tragedia de la "crisis de los refugiados". Las imágenes de Aylan generaron una oleada de indignación y solidaridad en la sociedad civil y, en los días posteriores, los representantes políticos cambiaron su discurso sobre la gestión de las fronteras y la crisis de los refugiados. A raíz de la ola emocional generada por esta foto han nacido numerosos movimientos sociales e iniciativas a favor de las personas refugiadas, por ejemplo, en Tenerife, la plataforma Bienvenidos Refugiados, Candelaria Ciudad Refugio o el proyecto Acogida Comunitaria. El caso de Aylán Kurdi ha mostrado la capacidad de las redes sociales para crear narrativas alternativas al discurso institucional sobre las migraciones y las fronteras. La imagen de Aylan ha sido reutilizada, resignificada e interpretada creativamente en cientos de campañas, de iniciativas, de performances, de viñetas y memes que denunciaban la incapacidad europea frente al drama de los refugiados.

Si estos ejemplos muestran cómo hoy en día los movimientos sociales, las ONG y la ciudadanía en general pueden jugar un papel muy importante en la redefinición "humanitaria" de un espacio fronterizo, existen también numerosos ejemplos de la existencia de un círculo vicioso entre el discurso de los medios de comunicación, el discurso político xenófobo y la opinión pública que transforman los muros y las vallas en símbolos de la separación entre "nosotros" y "ellos", como en el caso de la retórica política alrededor del reforzamiento del muro que separa Estados Unidos de México. En este caso, la función de numerosas vallas, muros o concertinas, a menudo no es solamente obstaculizar la entrada de personas no deseadas, sino materializar y espectacularizar las fronteras morales. Los muros y las concertinas se transforman en un instrumento de propaganda política. Además, las actitudes hostiles o indiferentes de la sociedad hacia determinados colectivos de inmigrantes pueden legitimar, normalizar y justificar la violencia en las fronteras y la sistemática violación de su derechos humanos, como la devolución en caliente, la omisión de socorro, los controles en base a perfiles raciales, etc.

En este caso, los espacios físicos del control fronterizo, la opinión pública y los medios de comunicación interactúan creando un "espectáculo de la frontera", en la cual la "ilegalidad" se hace dramática y espectacularmente visible: la mediatización del control fronterizo, la construcción de la llegada de personas inmigrantes en situación administrativa irregular como una "invasión", una "masa peligrosa", contribuye a reforzar no solo las fronteras físicas, sino las fronteras simbólicas que excluyen a las personas migrantes en situación administrativa irregular de la comunidad de personas con derechos. 


\section{Recuadro 2. El "efecto llamada": alcance y limitaciones del concepto}

En los discursos políticos y mediáticos suele brotar el "efecto llamada" cuando se trata de criticar una política migratoria que se considera insuficientemente restrictiva, sea por la permisividad en el control de las fronteras o sea por las posibilidades que se ofrecen a las personas inmigrantes en situación irregular para regularizar su situación. Se argumenta que estas facilidades atraen a otras personas que, en condiciones menos favorables, no elegirían España como destino de sus proyectos migratorios.

La función que cumple el recurso discursivo del "efecto llamada" estriba en la posibilidad de evitar que el emisor del discurso tenga que explicitar que aboga por acciones que hagan el destino menos atractivo y que la disuasión migratoria incluye la prolongación de la irregularidad (y explotación laboral) y posiblemente la interpretación "flexible" del respeto a los derechos (devoluciones en caliente, fronteras móviles).

Es indudable que las personas migrantes, a la hora de fijarse en un posible destino de su movilidad, tienen en cuenta las condiciones de vida que esperan encontrar. Por consiguiente, empeorarlas puede generar disuasión (de difícil cuantificación). Pero el empeoramiento del trato dispensado a las personas inmigrantes trae consigo una factura: la constante amenaza de deportabilidad, con la correspondiente angustia generada para las personas afectadas, nutrir la economía sumergida de personas desprovistas de derechos laborales y facilitar los discrusos xenófobos son costes que figuran entre las contraindicaciones de la disuasión del tipo "no es país para inmigrantes". Para no hablar de la sombra que introduce en el autoconcepto de una sociedad que se enorgullece de respetar los derechos fundamentales de todas las personas.

\section{A modo de conclusión}

Las Islas Canarias forman parte de una de las rutas de la emigración africana hacia el continente europeo. Después del auge temporal del uso de esta ruta durante los años 2005 a 2007, su peso en las llegadas al continente europeo había caído hasta el 0,2\% del total en 2017, con un repunte incipiente en 2018. Las islas europeas son puntos de llegada a la frontera exterior de la Unión Europea y su protagonismo cambiante en las migraciones de tránsito en esta red de rutas depende de las permeabilidades relativas de cada una ellas. Las acciones de control migratorio en destino, origen y lugares de tránsito, los focos variables de inestabilidad geopolítica y la mutación de las rutas terrestres en el continente africano condicionan esta (im)permeabilidad.

En los discursos mediáticos sobre la inmigración las llegadas en pateras y cayucos cuentan con un protagonismo muy superior a su peso en los flujos migratorios. Esta sobreponderación se manifiesta generalmente en dos tipos de encuadres noticiosos, el securitario y el humanitario. Ambos provocan reacciones emocionales en la opinión pública. El primero provoca sensaciones de inseguridad y miedo, el segundo empatía y solidaridad. Es en esta ambigüedad donde se mueve la relación de la sociedad europea con sus fronteras. 
Para ampliar la información:

FRONTEX (2018), Risk Analysis for 2018, Warsaw. [www.frontex.europa.eu]

Godenau, D. y Zapata Hernández, V.M. (2008), "The Case of the Canary Islands (Spain): A Region of Transit between Africa and Europe", in Pinyol, G. (ed.), Immigration flows and the management of the EU's southern maritime borders, Editor CIDOB, Barcelona.

López-Sala, A. y Godenau, D. (eds.) (2018), Estados de contención, estados de detención. El control de la inmigración irregular en España, Anthropos Editorial, Barcelona.

\section{Cómo citar este artículo:}

Godenau, D. y Buraschi, D. (2018). Las migraciones marítimas irregulares: las islas en la red de rutas. OBITen Factsheet 2-2018. Recuperado de www.obiten.net.

El Observatorio de la Inmigración de Tenerife es una iniciativa conjunta del Cabildo de Tenerife y la Universidad de La Laguna que surge con vocación de estructura permanente y dinámica para avanzar en el conocimiento científico de los movimientos migratorios. OBITen desarrolla su actividad a modo de centro de recopilación, producción y difusión de información que facilita la opinión cualificada y favorece la toma de decisiones que redunden en una mejor gestión del fenómeno inmigratorio y sus implicaciones.

http://www.obiten.net 